\title{
Ultrashortwave radiation promotes the recovery of spinal cord injury by inhibiting inflammation via suppression of the MK2/TNF- $\alpha$ pathway
}

\author{
NAN WANG ${ }^{1,2 *}$, ZHIPING FENG $^{1 *}$, WEI ZHAO ${ }^{2}$, ZHIQIANG ZHANG $^{1}$ and LIXIN ZHANG ${ }^{1}$ \\ ${ }^{1}$ Department of Rehabilitation, Shengjing Hospital of China Medical University, Shenyang, Liaoning 110022; \\ ${ }^{2}$ The 4th Department of Orthopedic Surgery, Central Hospital Affiliated to Shenyang Medical College, \\ Shenyang, Liaoning 110024, P.R. China
}

Received November 8, 2017; Accepted July 12, 2018

DOI: $10.3892 /$ ijmm.2018.3786

\begin{abstract}
Mitogen-activated protein kinase-activated protein kinase 2 (MK2) and its mediated inflammation are involved in various diseases, including spinal cord injury (SCI). Ultrashortwave (USW) radiation has previously been reported to exert a protective effect on SCI. In the present study, through a series of reverse transcription-quantitative polymerase chain reaction (RT-qPCR), western blot and immunofluorescence assay, it was found that MK2 and tumor necrosis factor (TNF)- $\alpha /$ interleukin (IL)-1 $\beta$ were elevated in patients with SCI and in $\mathrm{H}_{2} \mathrm{O}_{2}$-treated C8-D1A cells. Through gene level and protein level detection by using of RT-qPCR, western blot, immunofluorescence assay and terminal deoxynucleotidyl transferase (TdT) dUTP nick-end labeling assay, it was demonstrated that USW radiation inhibited the expression of MK2/TNF- $\alpha / \mathrm{IL}-1 \beta$ and suppressed the apoptosis of $\mathrm{H}_{2} \mathrm{O}_{2}$-treated C8-D1A cells. Furthermore, it was confirmed that the overexpression of MK2 reversed the protective effect of USW on C8-D1A cells, which indicated that USW achieved its function via regulation of the MK2/TNF- $\alpha / \mathrm{IL}-1 \beta$ pathway. Finally, using a constructed in vivo model and a series of RT-qPCR, western blot and IHC detection, it was confirmed that USW suppressed the expression of MK2 to promote functional recovery following SCI.

The findings of the present study may provide a novel target and improve on the current understanding of how USW functions in the treatment of SCI.
\end{abstract}

Correspondence to: Professor Lixin Zhang, Department of Rehabilitation, Shengjing Hospital of China Medical University, 39 Huaxiang Road, Tiexi, Shenyang, Liaoning 110022, P.R. China E-mail: uzhanglx@aliyun.com

*Contributed equally

Key words: ultrashortwave, spinal cord injury, mitogen-activated protein kinase-activated protein kinase 2 , tumor necrosis factor- $\alpha$, inflammation

\section{Introduction}

Traumatic spinal cord injury (SCI) is a problematic disease that results in a substantial burden on human society, and has a marked effect on the mind and body of patients $(1,2)$. In general, the pathological process of SCI is divided into two stages: The acute phase and subacute phase, in which secondary damage to central nervous system (CNS) tissue occurs due to a variety of factors, including ischemia, hemorrhage, excitotoxic damage and inflammation (3). It is widely accepted that innumerable cytokines and signaling pathways mediating the inflammatory response contribute to the secondary damage following SCI (4-7).

Mitogen-activated protein kinase (MAPK)-activated protein kinase 2 (MK2) has been reported as a direct substrate of p38 $\alpha$ and p38 $\beta$ MAPKs, and is a novel molecular target for the anti-inflammatory response (8). Based on an animal study of Parkinson's disease, Gómez-Nicola found that MK2-knockout mice exhibited reduced neurotoxicity and reduced neuroinflammation (9). In addition, Tietz et al revealed that MK2 is key in the regulation and limitation of the immune response in the CNS (10). To date, there have been few studies on MK2 and SCI. Ghasemlou et al reported that a lack of MK2 contributed to a reduction in tissue damage following SCI and an improvement in locomotor recovery (11).

In our previous study, it was found that bone marrow stromal cell (BMSC) transplantation combined with exposure to USW (USW) radiation promoted tissue repair and functional recovery following SCI. It was also demonstrated that the transplantation of BMSCs combined with exposure to USW radiation inhibited ED1, a marker of activated macrophages, and the expression of glial fibrillary acidic protein, which indicated a weakening of the inflammatory response (12). In another previous study, it was found that USW therapy promotes nerve axon regeneration and Schwann cell proliferation (13). The present study focused on the effect of USW radiation on astrocyte inflammation. Using $\mathrm{H}_{2} \mathrm{O}_{2}$-treated astrocyte $\mathrm{SCI}$ cell models and construction of an SCI rat model, it was revealed that USW radiation inhibited the MK2-mediated inflammatory response and promoted the repair of SCI. The findings of the present study provide an improved understanding of USW radiation in the treatment of SCI. 


\section{Materials and methods}

Patients and tissue samples. Serum specimens from 20 cases of patients with acute SCI and paired serum specimens from 20 cases without SCI were collected at Shengjing Hospital of China Medical University (Shenyang, China) between January 2016 and December 2016. All cases were diagnosed according to the American Spinal Injury Association (ASIA; 2011) (14). Written informed consent was obtained from the patients whose serum specimens were used in the present study. The Institute Research Medical Ethics Committee of Shengjing Hospital of China Medical University granted approval for the study.

Astrocyte culture. C8-D1A murine astrocytes (cat. no. CRL-2541) were purchased from America Type Culture Collection (Manassas, VA, USA. The culture medium consisted of Dulbecco's Modified Eagle's Medium (DMEM; Gibco; Thermo Fisher Scientific, Inc.) supplemented with $10 \%$ (v/v) fetal bovine serum (Invitrogen; Thermo Fisher Scientific, Inc.), $100 \mathrm{IU} / \mathrm{ml}$ penicillin and $100 \mathrm{mg} / \mathrm{ml}$ streptomycin (Baomanbio, Shanghai, China). All C8-D1A cells were maintained at $37^{\circ} \mathrm{C}$ in a humidified atmosphere containing $5 \% \mathrm{CO}_{2}$. The culture medium was replaced every third day. Cells were passaged with a ratio of 1:4 when growing to $80 \%$ confluence.

$\mathrm{H}_{2} \mathrm{O}_{2}$ intervention and USW radiation exposure. For the $\mathrm{H}_{2} \mathrm{O}_{2}$ intervention, $200 \mu \mathrm{M} \mathrm{H}_{2} \mathrm{O}_{2}$ was added to different groups of C8-D1A cells $\left(5 \times 10^{5}\right)$ for $12 \mathrm{~h}$, according to a previous study (14), and these were then harvested for subsequent detection. For the USW radiation exposure, a USW device (Shanghai Electrical Device Company, Shanghai, China) was used for USW radiation exposure at a frequency of $40.68 \mathrm{MHz}$, with a maximum and actual export power of $11.32 \mathrm{~W}$.

Plasmid construction and transfection. The full length MK2 was amplified and cloned into the KpnI and XhoI restriction sites (Promega Corporation, Madison, WI, USA) of the pcDNA3.1 vector (Invitrogen; Thermo Fisher Scientific, Inc.) to synthetize an MK2-overexpression plasmid (pcDNA3.1-MK2). The pcDNA3.1-MK2 plasmids were transfected into the cultured C8-D1A cells in the presence of $\mathrm{H}_{2} \mathrm{O}_{2}$ to construct the MK2-overexpression SCI cell model by using of Lipofectamine 2000 (Invitrogen; Thermo Fisher Scientific, Inc.). The pcDNA3.1 vector was transfected into cells in the control SCI cell model. Total RNAs and total proteins were harvested $24 \mathrm{~h}$ following transfection for further detection.

Immunofluorescence analysis. The immunofluorescence procedure was performed as previously reported (15). Briefly, the $\mathrm{C} 8$-D1A cells $\left(5 \times 10^{5}\right)$ were passaged onto glass coverslips $(0.8 \times 0.8 \mathrm{~cm})$ and cultured to $50-60 \%$ confluence. Following rinsing twice with PBS, the coverslips were fixed with $4 \%$ paraformaldehyde for $15 \mathrm{~min}$ and blocked with 5\% BSA (Cell Signaling Technologies, Inc., Danvers, MA, USA) for $1 \mathrm{~h}$ at room temperature. Subsequently, rabbit anti-MK2 antibody (Abcam, Cambridge, UK; 1:100; cat. no. ab131504) was added for incubation at $4^{\circ} \mathrm{C}$ overnight. The following day, following incubation with fluorescent secondary antibodies (1:200; cat. no. ab150081, Abcam) at room temperature for $1 \mathrm{~h}$, the coverslips were observed under a fluorescent microscope (Leica Microsystems GmbH, Wetzlar, Germany). Images were captured and analyzed using Image-Pro Plus 6.0 software (Media Cybernetics, Inc., Rockville, MD, USA).

Reverse transcription-quantitative polymerase chain reaction $(R T-q P C R)$ analysis. All the procedures were performed as described previously (16). In brief, total RNA was extracted using TRIzol (Invitrogen; Thermo Fisher Scientific, Inc.) according to the manufacturer's protocol. cDNA was synthesized using the PrimeScript RT Reagent kit (Takara Biotechnology Co., Ltd., Dalian, China). The RT-qPCR analysis was performed using SYBR-Green Premix Ex Taq (Takara Biotechnology Co., Ltd.) on Light Cycler 480 system (Roche Diagnostics, Basel, Switzerland) according to the manufacturer's protocol. The expression of tumor necrosis factor (TNF)- $\alpha$, interleukin (IL)-1 $\beta$ and MK2 were calculated using $\beta$-actin as an internal control by the $2^{-\Delta \Delta C q}$ method (17). The primers used in the present study were as follows: TNF- $\alpha$, forward 5'-CCACGT CGTAGCAGCAAACCACCAAG-3' and reverse 5'-CAGGTA CATGGGCTCCTCATACC-3'; IL-1 $\beta$, forward 5'-CCCAAC TGGTACATCAGCACCTC-3' and reverse 5'-GACACGGAT TCCATGGTGAAGTC-3'; MK2, forward 5'-GACATGTGG TCCTTGGGTGTCATCATG-3' and reverse 5'-GAGATGGCA AGGCCGTGATTGGAATAG-3'; $\beta$-actin, forward 5'-AGTGTG ACGTGGACATCCGCAAAG-3' and reverse 5'-ATCCACATC TGCTGGAAGGTGGAC-3'. The thermocycling conditions were: Pre-denaturation at $95^{\circ} \mathrm{C}$ for $15 \mathrm{sec}$, followed by a denaturation at $95^{\circ} \mathrm{C}$ for $5 \mathrm{sec}$, annealing and extension at $60^{\circ} \mathrm{C}$ for $30 \mathrm{sec}$ for 45 cycles.

Western blot analysis. Total protein from the cells and tissue specimens were extracted using RIPA lysis buffer (Santa Cruz Biotechnology, Inc., Dallas, TX, USA). Protein concentration was quantified using the BCA protein assay kit (Santa Cruz Biotechnology, Inc.) A total of $40 \mu \mathrm{g}$ proteins were subjected to $10 \%$ SDS-PAGE and transferred onto a PVDF membrane, and then blocked by 5\% BSA (Cell Signaling Technologies, Inc.) for $1 \mathrm{~h}$ at room temperature. Each membrane was incubated with primary antibodies at $4{ }^{\circ} \mathrm{C}$ overnight, followed by incubation with secondary antibodies [goat anti-rabbit IgG horseradish peroxidase (HRP), 1:2,000; cat. no. ab205718; Abcam] at room temperature for $1 \mathrm{~h}$ the following day. The following antibodies were used: Rabbit anti-MK2 antibody (1:500); rabbit anti-TNF- $\alpha$ antibody (1:500; ab6671; Abcam) and rabbit anti-GAPDH antibody $(1: 10,000$; ab128915; Abcam). After three washes with TBST, an ECL Western Blotting Substrate Kit (cat. no. ab65623; Abcam) was applied for chemiluminescence imaging by using of Image J2X software (Rawak Software Inc., Stuttgart, Germany).

Terminal deoxynucleotidyl transferase (TdT) dUTP nick-end labeling (TUNEL) assay. Cell apoptosis was determined using a TUNEL assay, as previously described (18). Briefly, the C8-D1A cells were seeded on coverslips and were then fixed using $4 \%$ paraformaldehyde for $30 \mathrm{~min}$, followed by permeabilizing with $0.1 \%$ Triton X-100 for $2 \mathrm{~min}$ on ice. The cells were then labeled using a TUNEL kit (Nanjing Keygen Biotech Co., Ltd., Nanjing, China) according to the manufacturer's protocol. The apoptotic index was calculated using the 
following formula: Apoptotic index = (total number of apoptotic cells/total number of cells) x $100 \%$.

Establishment of animalmodels and Basso-Beattie-Bresnahan $(B B B)$ evaluation. All the procedures were performed as previously reported (12). A total of 48 Sprague-Dawley female rats (average weight: 180-220 g) with an average age of 12-weeks-old, provided by the Experimental Animal Center at Shengjing Hospital of China Medical University, were randomly divided into three groups $(n=16$ each): Sham-operated group, control group (SCI animals) and USW group (SCI animals exposed to USW radiation). All animals were housed in a condition of $20-25^{\circ} \mathrm{C}$ with $6-80 \%$ humidity and all animals were maintained under a $12 \mathrm{~h}$ light/dark cycle with free access to food and water. Spinal cord contusion was inflicted using Allen's method (Allen, 1911) when the animals were under intraperitoneal anesthesia (12). A 2-cm midline incision was made over the T9-T11 spinal region, and the soft tissue and T9-T11 vertebrae were removed. Laminectomy was performed at the T10 level under a surgical microscope, avoiding dura matter laceration. The spinal cord was injured using a modified Allen's impactor, where a guided 9-g rod was dropped $10 \mathrm{~cm}$ onto the exposed dura mater, representing moderate SCI. Following recovery from anesthesia, the rats exhibited paralysis of both hind limbs, urine and stool disorder, mental weakness, and slow and poor feeding, and received manual bladder expression twice daily until recovery of sphincter control. For the postoperative treatment of animals in the USW group, a pair of disc electrodes $4 \mathrm{~cm}$ in diameter was placed bilaterally on the T9-T11 vertebrae at a distance of $2 \mathrm{~cm}$ from the skin. The USW device (Shanghai Electrical Device Company) was operated at a frequency of $40.68 \mathrm{MHz}$, with maximum and actual export powers of 40 and $11.32 \mathrm{~W}$, respectively. USW treatment was executed daily with a radiating exposure of $7 \mathrm{~min} /$ time until the animals were sacrificed.

A 21-point BBB scale was used to assess the hind limb locomotor function (19). The tests were performed prior to surgery and at 1-week intervals following SCI for 4 weeks. The animals were placed individually on an open field (radius, $90 \mathrm{~cm}$ ) and allowed to move freely for $4 \mathrm{~min}$. Performance was evaluated by two experienced observers blinded to the treatment groups.

Immunohistochemistry. All the procedures were performed as described previously (20). In brief, tissue slides (4- $\mu \mathrm{m}$ thick) were incubated with a TNF- $\alpha / \mathrm{MK} 2$ primary antibody at $4^{\circ} \mathrm{C}$ overnight, and subsequently incubated with biotinylated secondary antibodies ( $2 \mu \mathrm{g} / \mathrm{ml}$; Abcam) at $37^{\circ} \mathrm{C}$ for $30 \mathrm{~min}$. This was followed by streptavidin-HRP complex incubation and diaminobenzidine tetrahydrochloride (Abcam) staining, and hematoxylin (Abcam) counterstaining. All slides were assessed independently under a Leica DMILLED inverted microscope (Olympus Corporation, Tokyo, Japan) by two experienced pathologists, who were blinded to patient clinical pathology and other information. The expression level of TNF- $\alpha /$ MK2 was evaluated as described previously (21).

Statistical analysis. All data are presented as the mean \pm standard deviation and were analyzed using GraphPad Prism 5.0 software (GraphPad Software, Inc., La Jolla, CA,
USA). $\mathrm{P}<0.05$ was considered to indicate a statistically significant difference. Two-way analysis of variance was used to compare groups (between-subject) and time following surgery (within-subject and repeated measures), and one-way analysis of variance was used to examine differences in the between-subject factor. A post hoc Bonferroni test was used when necessary to examine specific differences between groups.

\section{Results}

MK2 is elevated in patients with $\mathrm{SCI}$ and $\mathrm{H}_{2} \mathrm{O}_{2}$-treated C8-D1A cells. The expression of MK2 was detected in serum specimens of 20 patients with SCI and in paired serum specimens of 20 patients without SCI. As shown in Fig. 1A and B, the expression of MK2 was elevated in serum specimens of patients with SCI, compared with that in serum specimens of patients without SCI $(\mathrm{P}<0.01)$. Secondly, $\mathrm{H}_{2} \mathrm{O}_{2}$ was used to simulate an astrocyte inflammation cell model. As shown in Fig. $1 C$ and D, the expression levels of TNF- $\alpha$ and IL-1 $\beta$, two common markers of inflammation, were significantly increased in the $\mathrm{H}_{2} \mathrm{O}_{2}$-treated C8-D1A cells, compared with those in the control group $(\mathrm{P}<0.01)$. Thirdly, the expression of MK2 was measured at the cellular level. As shown in Fig. 1E-G, the expression of MK2 was also elevated in the $\mathrm{H}_{2} \mathrm{O}_{2}$-treated C8-D1A cells $(\mathrm{P}<0.01)$. All the above findings indicated that an elevated level $\mathrm{MK} 2$ was present in patients with $\mathrm{SCI}$ and in the $\mathrm{H}_{2} \mathrm{O}_{2}$-treated astrocyte cell model.

USW radiation inhibits the inflammatory response and apoptosis in C8-DIA cells. In our previous study, it was found that USW therapy combined with BMSC transplantation promoted the functional recovery of SCI in rats (12). Therefore, the present study examined whether USW radiation was able to alleviate the astrocyte inflammatory response following SCI at the cellular level. The expression levels of TNF- $\alpha$ and IL-1 $\beta$ were detected in each group. As shown in Fig. 2A and B, compared with the control group, the expression levels of TNF- $\alpha$ and IL- $1 \beta$ in the $\mathrm{H}_{2} \mathrm{O}_{2}$ group and $\mathrm{H}_{2} \mathrm{O}_{2}+\mathrm{USW}$ group were elevated $(\mathrm{P}<0.01)$. Compared with the $\mathrm{H}_{2} \mathrm{O}_{2}$ group, the expression levels of TNF- $\alpha$ and IL-1 $\beta$ in the $\mathrm{H}_{2} \mathrm{O}_{2}+$ USW group were significantly decreased $(\mathrm{P}<0.05)$. These results indicated that USW radiation alleviated the inflammatory response of the astrocytes following USW exposure. In addition, the expression of MK2 was measured in the above-mentioned cell models. As shown in Fig. 2C and D, USW radiation inhibited the expression of MK2 in the $\mathrm{H}_{2} \mathrm{O}_{2}$-treated C8-D1A cells $(\mathrm{P}<0.05)$. Furthermore, the effect of USW treatment on the apoptosis of C8-D1A cells was determined using a TUNEL assay. As shown in Fig. 2E, USW treatment inhibited cell apoptosis in the $\mathrm{H}_{2} \mathrm{O}_{2}$-treated $\mathrm{C} 8$-D1A cells $(\mathrm{P}<0.01)$. The above results supported the hypothesis that USW radiation alleviates the inflammatory response and apoptosis following $\mathrm{H}_{2} \mathrm{O}_{2}$ intervention, and it was revealed that USW radiation had a protective effect in astrocytes following $\mathrm{H}_{2} \mathrm{O}_{2}$ intervention.

Upregulation of $M K 2$ reverses the protective effect USW radiation on $C 8-D 1 A$ cells. As described above, it was found that USW radiation alleviated the inflammatory response and inhibited the expression of $\mathrm{MK} 2$ in $\mathrm{H}_{2} \mathrm{O}_{2}$-treated C8-D1A cells. 

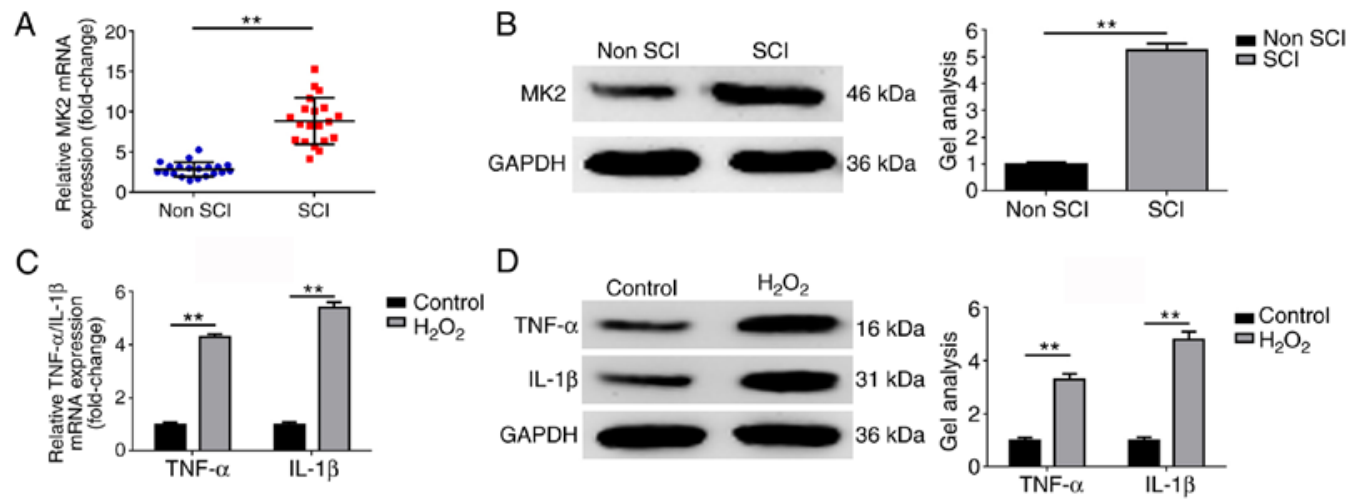

E

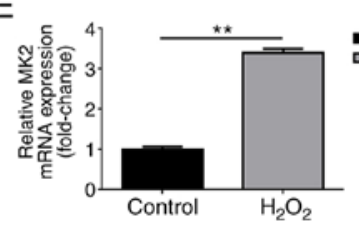

F
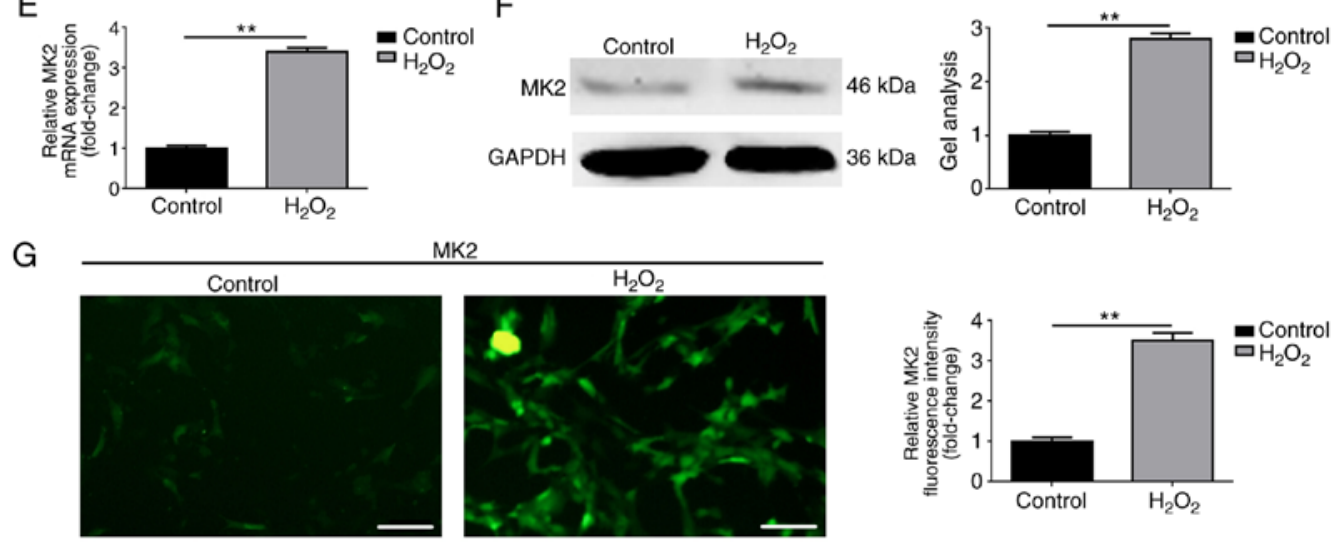

MK2
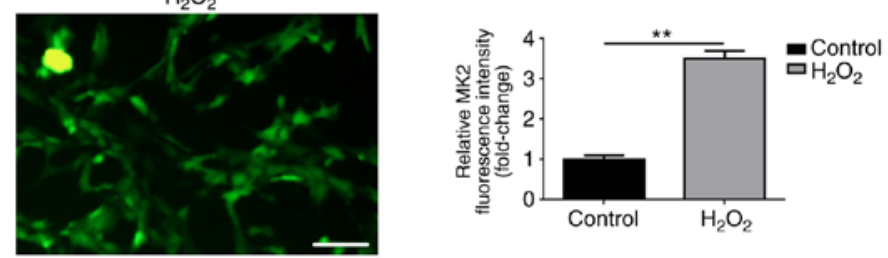

Figure 1. MK2 is elevated in patients with SCI and $\mathrm{H}_{2} \mathrm{O}_{2}$-treated C8-D1A cells. MK2 was elevated in patients with SCI, compared with non SCI group as determined by (A) RT-qPCR and (B) western blot analyses. ${ }^{* *} \mathrm{P}<0.01$, vs. non SCI group. Expression levels of TNF- $\alpha$ and IL- $1 \beta$ were also elevated in the patients with SCI, compared with the non SCI group, as determined by (C) RT-qPCR and (D) western blot analyses. ${ }^{* *} \mathrm{P}<0.01$, vs. non SCI group. MK2 was upregulated in $\mathrm{H}_{2} \mathrm{O}_{2}$-treated C8-D1A cells, compared with the control group, as detected by (E) RT-qPCR, (F) western blot and (G) immunofluorescence analyses (magnification, $\mathrm{x} 200$; scale bar $=100 \mu \mathrm{m}$ ). ${ }^{* *} \mathrm{P}<0.01$, vs. control group. SCI, spinal cord injury; MK2, mitogen-activated protein kinase-activated protein kinase 2; IL interleukin; TNF- $\alpha$, tumor necrosis factor- $\alpha$; RT-qPCR, reverse transcription-quantitative polymerase chain reaction.
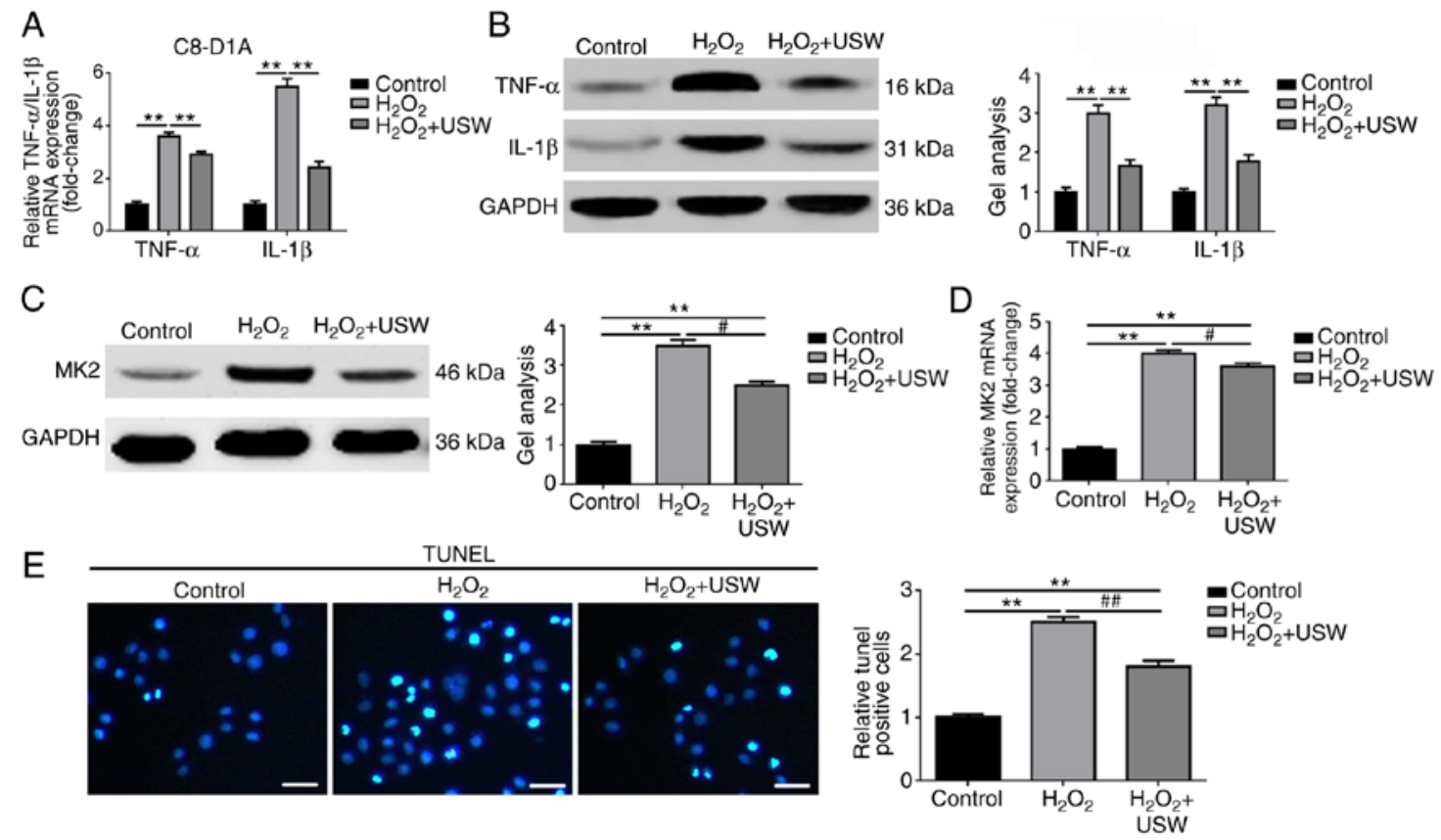

Figure 2. USW radiation inhibits the inflammatory response and apoptosis in C8-D1A cells. USW radiation inhibited the expression of TNF- $\alpha$ and IL-1 $\beta$ in $\mathrm{H}_{2} \mathrm{O}_{2}$-treated C8-D1A cells, compared with the control group, as detected by (A) RT-qPCR and (B) western blot analyses. ${ }^{* *} \mathrm{P}<0.01$ vs. control group; ${ }^{\#} \mathrm{P}<0.05$, vs. $\mathrm{H}_{2} \mathrm{O}_{2}$ group. USW radiation inhibited the expression of $\mathrm{MK} 2$ in $\mathrm{H}_{2} \mathrm{O}_{2}$-treated C8-D1A cells, compared with the control group, as detected by (C) western blot and (D) RT-qPCR analyses. ${ }^{* *} \mathrm{P}<0.01$, vs. control group; ${ }^{~} \mathrm{P}<0.05$, vs. $\mathrm{H}_{2} \mathrm{O}_{2}$ group. (E) USW radiation inhibited apoptosis of $\mathrm{H}_{2} \mathrm{O}_{2}$-treated C8-D1A cells, compared with the control group, as determined using a TUNEL assay (magnification, $\mathrm{x} 400$; scale bar $=75 \mu \mathrm{m}$ ). ${ }^{* *} \mathrm{P}<0.01$, vs. control group; ${ }^{\# /} \mathrm{P}<0.05$, vs. $\mathrm{H}_{2} \mathrm{O}_{2}$ group. USW, ultrashortwave; MK2, mitogen-activated protein kinase-activated protein kinase 2; IL interleukin; TNF- $\alpha$, tumor necrosis factor- $\alpha$; RT-qPCR, reverse transcription-quantitative polymerase chain reaction; TUNEL, terminal deoxynucleotidyl transferase (TdT) dUTP nick-end labeling. 
A
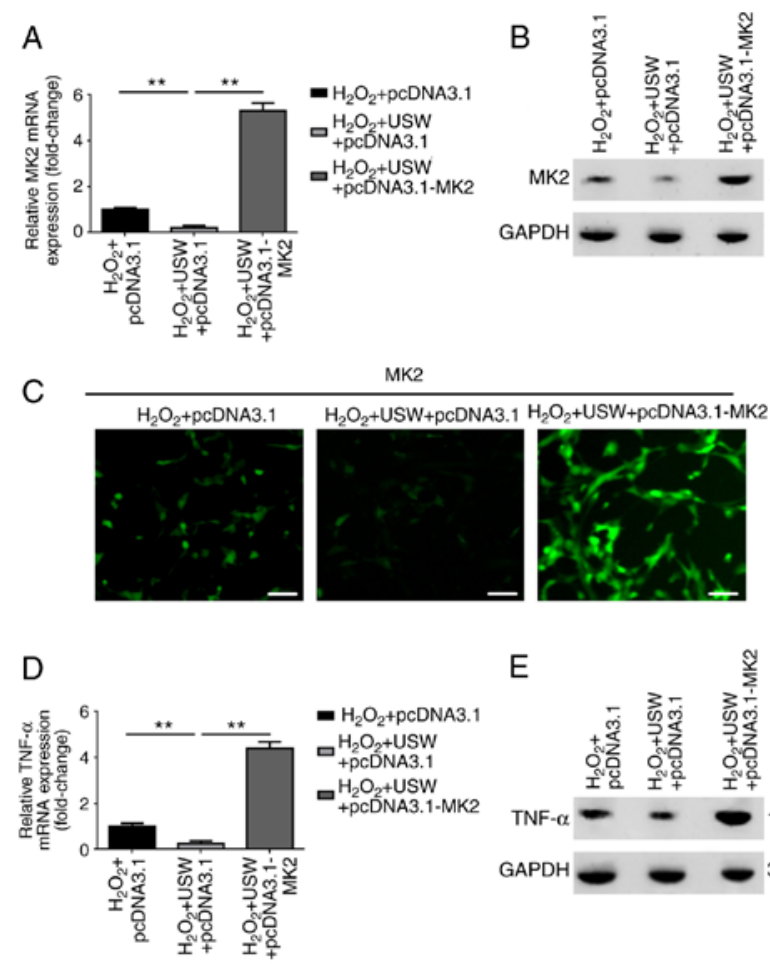

$\mathrm{F}$
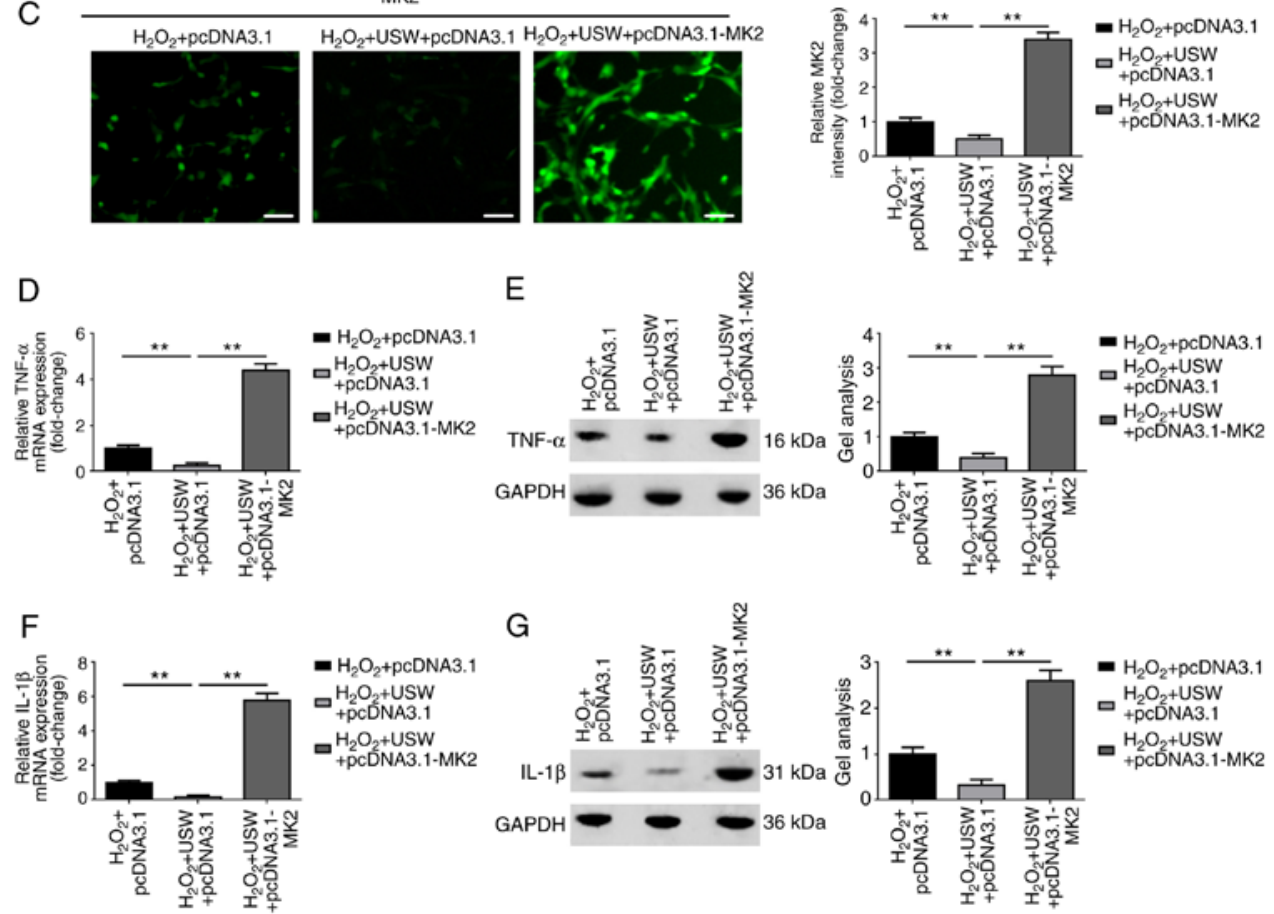

C
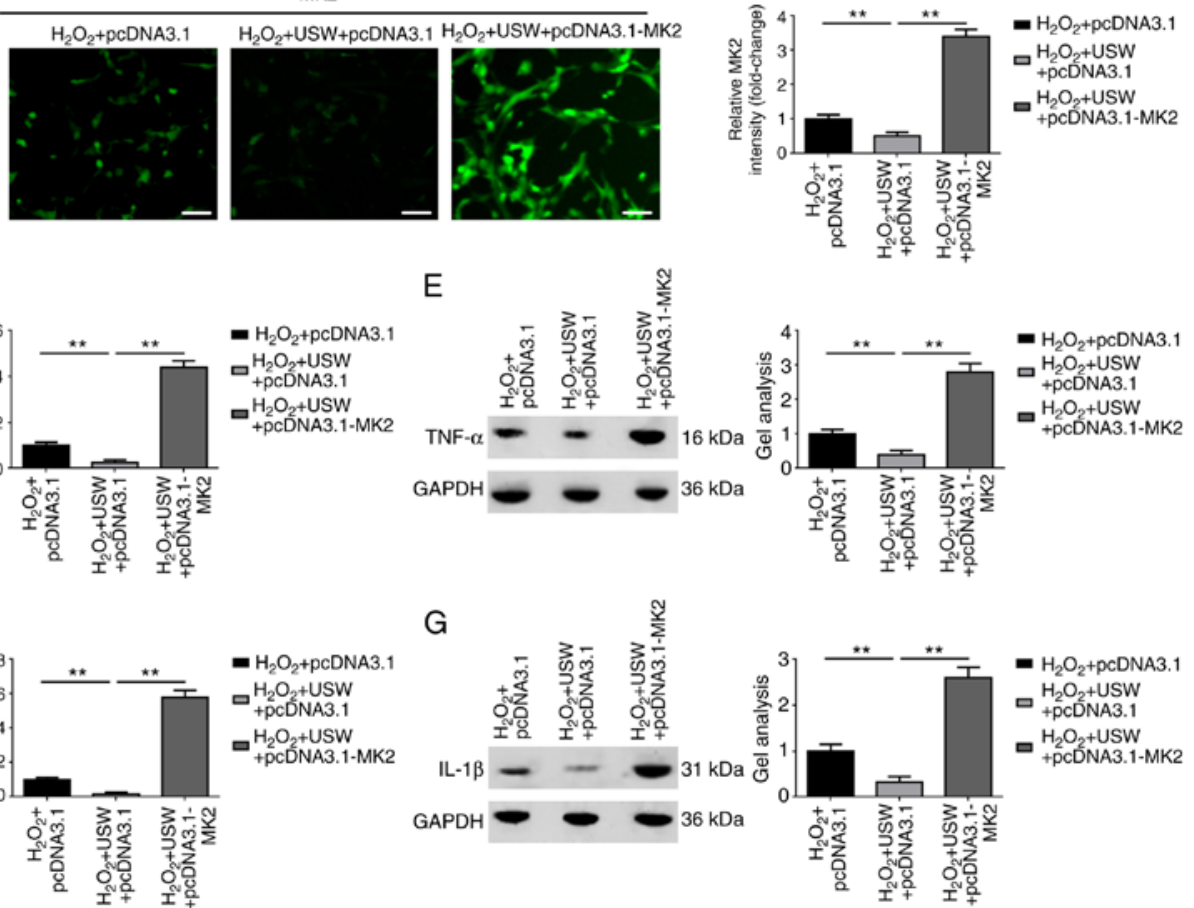

$\mathrm{H}$

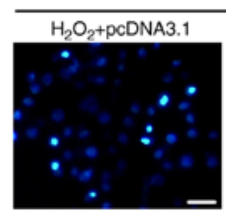

Apoptosis
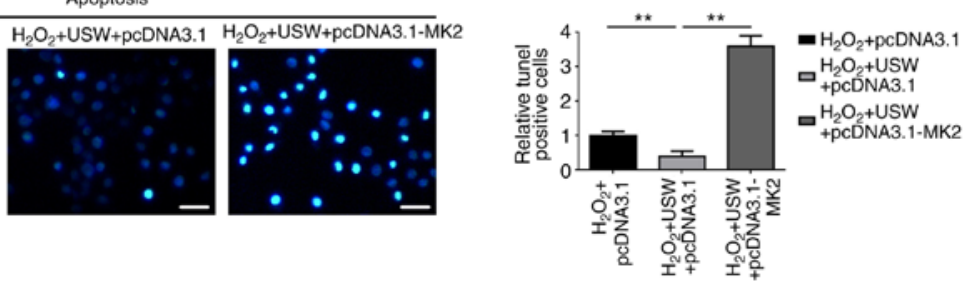

Figure 3. Upregulation of MK2 reverses the protective effect USW radiation on C8-D1A cells. Expression of MK2 in USW radiation-treated C8-D1A cells was elevated by transfection with pcDNA3.1-MK2, as detected by (A) RT-qPCR, (B) western blot and (C) immunofluorescence analyses (Magnification, x200; scale bar $=100 \mu \mathrm{m}) .{ }^{* *} \mathrm{P}<0.01$, vs. $\mathrm{H}_{2} \mathrm{O}_{2}+\mathrm{USW}+$ pcDNA3.1 group. Elevation of MK2 reversed the inhibitory effect USW radiation on TNF- $\alpha$, as determined by (D) RT-qPCR and (E) western blot analyses, and on IL-1 $\beta$, as determined by (F) RT-qPCR and (G) western blot analyses. ${ }^{* *} \mathrm{P}<0.01, \mathrm{vs} . \mathrm{H}_{2} \mathrm{O}_{2}+\mathrm{USW}+$ pcDNA3.1 group. $(\mathrm{H})$ Overexpression of MK2 attenuated the suppressive effect USW radiation on apoptosis, as detected using a TUNEL assay (magnification, $\mathrm{x} 400$; scale bar $=75 \mu \mathrm{m}){ }^{* * *} \mathrm{P}<0.01$, vs. $\mathrm{H}_{2} \mathrm{O}_{2}+\mathrm{USW}+$ pcDNA3.1 group. USW, ultrashortwave; MK2, mitogen-activated protein kinase-activated protein kinase 2; IL interleukin; TNF- $\alpha$, tumor necrosis factor- $\alpha$; RT-qPCR, reverse transcription-quantitative polymerase chain reaction; TUNEL, terminal deoxynucleotidyl transferase (TdT) dUTP nick-end labeling.

Therefore, whether the protective effect of USW radiation on the inflammatory response was achieved through the MK2 pathway was investigated. An MK2-overexpression plasmid (pcDNA3.1-MK2) was constructed, and the constructed pcDNA3.1-MK2 plasmid was then transfected into the USW radiation-treated C8-D1A cells. As shown in Fig. 3A-C, transfection of the cells with pcDNA3.1-MK2 led to a significant elevation in the expression of MK2 in the USW radiation-treated C8-D1A cells $(\mathrm{P}<0.01)$. It was also confirmed that the elevation of MK2 promoted the expression of TNF- $\alpha$ and IL-1 $\beta$ with the presence of USW radiation (Fig. 3D-G; P<0.01). In addition, the results revealed that the overexpression of MK2 promoted C8-D1A cell apoptosis in the presence of USW radiation (Fig. $3 \mathrm{H} ; \mathrm{P}<0.01$ ). Therefore, the findings revealed that the upregulation of MK2 reversed the protective effect $\mathrm{USW}$ radiation on the $\mathrm{C} 8 \mathrm{-D} 1 \mathrm{~A}$ cells.

USW suppresses the expression of $M K 2$ and promotes functional recovery following SCI in vivo. To further confirm the protective effect of USW radiation on SCI in vivo, an SCI rat model was constructed as previously reported (12). USW radiation was applied in treating the rats in the USW group (Fig. 4A). As shown in Fig. 4B, compared with the sham surgery group, the average BBB scores of the control 

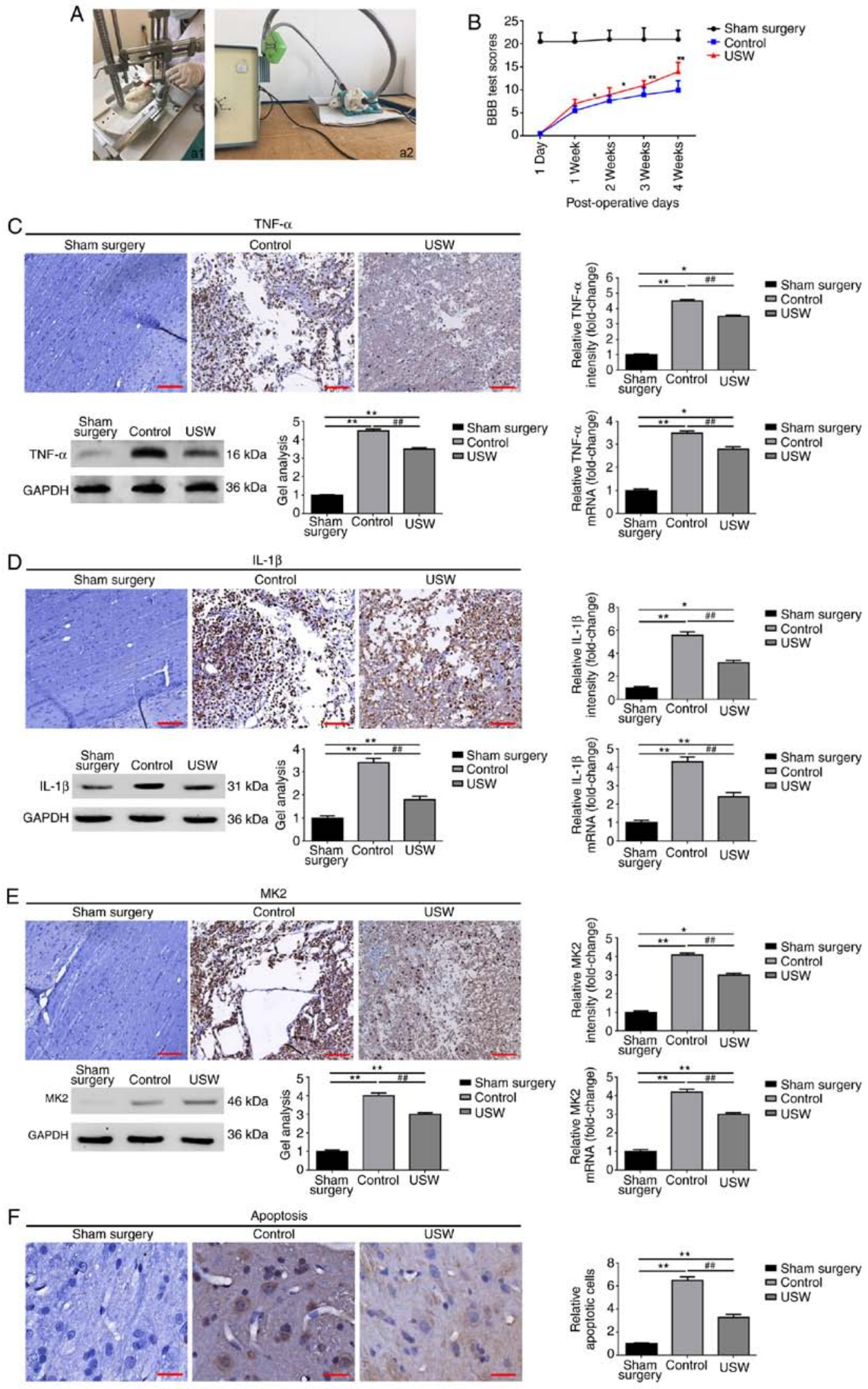

Figure 4. USW radiation suppresses the expression of MK2 and promotes functional recovery following SCI in rats. (A) Construction of SCI models using (a1) Allen's methods and (a2) USW treatment. (B) BBB score system was applied to evaluate the changes in locomotor function following USW radiation intervention. ${ }^{*} \mathrm{P}<0.05$ and ${ }^{* *} \mathrm{P}<0.01$, vs. control group. USW radiation inhibited the expression of (C) TNF- $\alpha$ and (D) IL-1 $1 \beta$ in vivo, as determined by IHC (magnification, $\mathrm{x} 100$; scale bar $=200 \mu \mathrm{m}$ ), western blot and a RT-qPCR analyses. ${ }^{*} \mathrm{P}<0.05$ and ${ }^{* * *} \mathrm{P}<0.01$, vs. sham surgery group; ${ }^{\# \#} \mathrm{P}<0.01$, vs. control group. (E) Expression of MK2 was decreased by USW radiation in vivo, as determined by IHC (magnification, x100; scale bar, $200 \mu \mathrm{m}$ ), western blot and RT-qPCR analyses. "P<0.05 and ${ }^{* *} \mathrm{P}<0.01$, vs. sham surgery group; ${ }^{\# \#} \mathrm{P}<0.01$, vs. control group. (F) USW radiation suppressed apoptosis following SCI, as measured using IHC (magnification, $\mathrm{x} 400$; scale bar $=50 \mu \mathrm{m}) .{ }^{* * *} \mathrm{P}<0.01$, vs. sham surgery group; ${ }^{\# \#} \mathrm{P}<0.01$, vs. control group. USW, ultrashortwave; $\mathrm{MK} 2$, mitogen-activated protein kinase-activated protein kinase 2; IL interleukin; TNF- $\alpha$, tumor necrosis factor- $\alpha$; BBB, Basso-Beattie-Bresnahan; RT-qPCR, reverse transcription-quantitative polymerase chain reaction. 


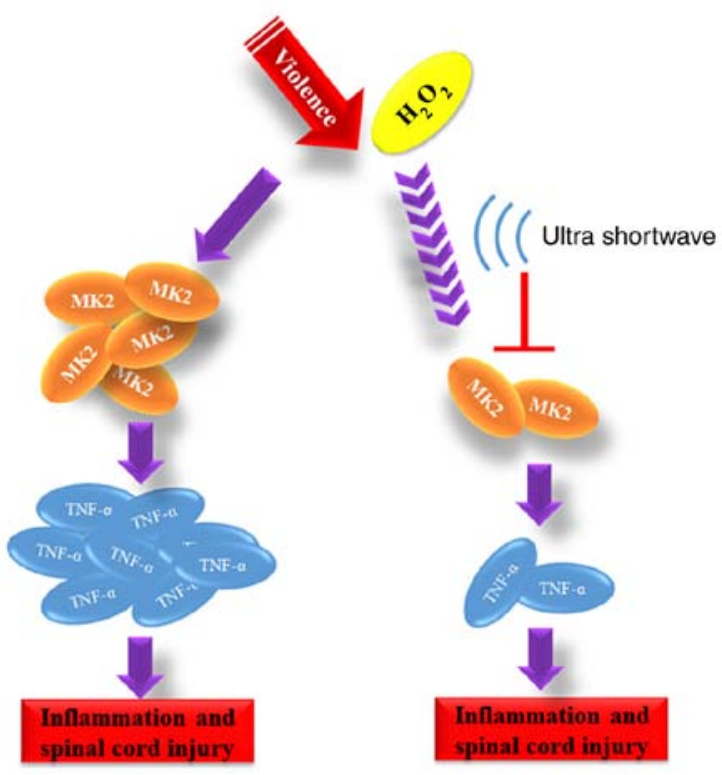

Figure 5. Schematic diagram of the proposed mechanism of the effect of ultrashortwave radiation on spinal cord injury. MK2, mitogen-activated protein kinase-activated protein kinase 2 ; TNF- $\alpha$, tumor necrosis factor- $\alpha$.

group and USW group were markedly decreased, indicating that the animal model was successfully constructed. When comparing the differences between the control group and USW group, it was found that the BBB scores in the USW group were prominently higher than those in the control group (Fig. 4B). These results demonstrated that USW promoted the functional recovery of SCI. The expression level of TNF- $\alpha$ was then determined in each group by IHC, RT-qPCR and western blot analyses. As shown in Fig. 4C and D, compared with the control group, USW radiation treatment markedly inhibited the expression of TNF- $\alpha$ and IL-1 $\beta$. The expression of MK2 was determined using the same methods and, as shown in Fig. 4F, USW radiation markedly suppressed the expression of MK2 in vivo. Finally, apoptosis in the animal model was determined. As shown in Fig. 4F, USW radiation significantly inhibited apoptosis in the SCI rats.

In brief, as the mechanism in Fig. 5 shows, the results described above confirmed that USW radiation promoted SCI recovery by inhibiting inflammation via suppression of the MK2/TNF- $\alpha$ pathway.

\section{Discussion}

Inflammation is an essential defense mechanism, which is vital in protecting against various pathogenic attacks, including SCI $(3,22,23)$. As a downstream substrate of p38 MAPKs and a novel molecular target of the anti-inflammatory response, MK2 is located at human chromosome 1q32.1 and functions as a key regulator in the treatment of inflammatory diseases, particularly in nervous system inflammation $(8,24)$. Ghasemlou et al reported that a lack of MK2 promoted locomotor recovery and reduced tissue damage following SCI (11). Kroner et al reported that MK2 facilitated TNF-induced M1 macrophage polarization following SCI (25). The present study focused on the expression and function of MK2 following SCI. It was found that the expression of MK2 was elevated in patients with $\mathrm{SCI}$ and in an $\mathrm{H}_{2} \mathrm{O}_{2}$-treated astrocyte cell model, which confirmed the role of MK2 as an inflammatory factor in SCI, as previously reported. In addition, through a constructed MK2-overexpression plasmid, the present study demonstrated that the elevation of MK2 reversed the protective effect of USW radiation on C8-D1A cells via promotion of the expression of TNF- $\alpha$ and IL-1 $\beta$.

As a downstream gene of MK2, TNF- $\alpha$ and IL-1 $\beta$ are known markers of various inflammatory conditions $(26,27)$. Tietz et al reported that TNF- $\alpha$ and IL- 6 signaling were mediated by the MK2 pathway, and that the knockdown of MK2 inhibited the expression of TNF- $\alpha /$ IL- 6 and protected against cerulein-induced pancreatitis (28). In the present study, TNF- $\alpha$ and IL-1 $\beta$ were selected as molecular markers in SCI-related inflammation. The cellular and animal experiments confirmed that TNF- $\alpha$ and IL- $1 \beta$ were elevated following the different inflammation-related interventions. Of note, it was revealed again that the up-regulation of MK2 led to elevated expression levels of TNF- $\alpha$ and IL-1 $\beta$, indicating that MK2 was upstream of these genes.

As a type of high frequency electric field, USW radiation exerts its function via a mechanism of heating and non-heating effects. A low field intensity of electric field $\left(40 \mathrm{~mW} / \mathrm{cm}^{2}\right)$ caused by a small dose of USW radiation may lead to full extension or contraction on cells and may result in biological effects via specific stimulation on cells or tissues. Pelletier et al reported that the direct exposure to current electric field stimulation resulted in morphological and molecular changes of brain cells (29). In the present study, it was confirmed that USW radiation alleviated the inflammatory response in $\mathrm{H}_{2} \mathrm{O}_{2}$-treated $\mathrm{C} 8$-D1A cells. In addition, it was confirmed that USW inhibited $\mathrm{H}_{2} \mathrm{O}_{2}$-induced apoptosis in C8-D1A cells. Furthermore, through in vivo experiments, the present study also demonstrated the protective effect of USW radiation on the constructed SCI rat model. In terms of the molecular mechanism, it was shown that USW radiation suppressed the expression of MK2 in the in vivo and in vitro experiments.

The inflammatory response of SCI and its treatment are complex issues. The findings of the present study revealed that USW promoted SCI recovery and alleviation of the inflammatory response following SCI via the suppression of MK2; however, the detailed mechanism of this effect on MK2 occurs remains to be fully elucidated. The results of the present study may provide a novel target in the molecular treatment of SCI.

\section{Acknowledgements}

Not applicable.

\section{Funding}

This study was supported by grants from National Natural Science Foundation of China (grant no. 81101462), the Liaoning Province Public Science Foundation (grant no. 2016 003001) and the Liaoning Province Natural Science Foundation (grant no. 201602875). 


\section{Availability of data and materials}

The analyzed datasets generated during the study are available from the corresponding author on reasonable request.

\section{Authors' contributions}

NW made substantial contributions to the analysis and interpretation of data; ZF and NW contributed equally to drafting the manuscript. WZ and ZZ made substantial contributions to the conception of the present study and conducted the statistical analysis. LZ critically revised the manuscript for important intellectual content.

\section{Ethics approval and consent to participate}

Written informed consent was obtained from the patients whose serum specimens were used in the present study. The Institute Research Medical Ethics Committee of Shengjing Hospital of China Medical University granted approval for the study.

\section{Patient consent for publication}

Not applicable.

\section{Competing interests}

The authors declare that they have no competing interests.

\section{References}

1. Stein DM and Sheth KN: Management of acute spinal cord injury. Continuum 21: 159-187, 2015.

2. Witiw CD and Fehlings MG: Acute spinal cord injury. J Spinal Disord Tech 28: 202-210, 2015.

3. David S, Zarruk JG and Ghasemlou N: Inflammatory pathways in spinal cord injury. Int Rev Neurobiol 106: 127-152, 2012.

4. Allison DJ and Ditor DS: Immune dysfunction and chronic inflammation following spinal cord injury. Spinal Cord 53: 14-18, 2015.

5. Ambrozaitis KV, Kontautas E, Spakauskas B and Vaitkaitis D: Pathophysiology of acute spinal cord injury. Medicina 42: 255-261, 2006 (In Lithuanian).

6. Bowes AL and Yip PK: Modulating inflammatory cell responses to spinal cord injury: All in good time. J Neurotrauma 31: 1753-1766, 2014.

7. Zhang N, Yin Y, Xu SJ, Wu YP and Chen WS: Inflammation \& apoptosis in spinal cord injury. Indian J Med Res 135: 287-296, 2012.

8. Duraisamy S, Bajpai M, Bughani U, Dastidar SG, Ray A and Chopra P: MK2: A novel molecular target for anti-inflammatory therapy. Expert Opin Ther Targets 12: 921-936, 2008.

9. Gómez-Nicola D, Valle-Argos B, Pita-Thomas DW and Nieto-Sampedro M: Interleukin 15 expression in the CNS Blockade of its activity prevents glial activation after an inflammatory injury. Glia 56: 494-505, 2008.

10. Tietz SM, Hofmann R, Thomas T, Tackenberg B, Gaestel M and Berghoff M: MK2 and Fas receptor contribute to the severity of CNS demyelination. PLoS One 9: e100363, 2014.

11. Ghasemlou N, Lopez-Vales R, Lachance C, Thuraisingam T, Gaestel M, Radzioch D and David S: Mitogen-activated protein kinase-activated protein kinase 2 (MK2) contributes to secondary damage after spinal cord injury. J Neurosci 30: 13750-13759, 2010.

12. Yin YM, Lu Y, Zhang LX, Zhang GP and Zhang ZQ: Bone marrow stromal cells transplantation combined with ultrashortwave therapy promotes functional recovery on spinal cord injury in rats. Synapse 69: 139-147, 2015.
13. Zhang LX, Tong XJ, Sun XH, Tong L, Gao J, Jia H and Li ZH: Experimental study of low dose ultrashortwave promoting nerve regeneration after acellular nerve allografts repairing the sciatic nerve gap of rats. Cell Mol Neurobiol 28: 501-509, 2008.

14. Kirshblum SC, Burns SP, Biering-Sorensen F, Donovan W, Graves DE, Jha A, Johansen M, Jones L, Krassioukov A, Mulcahey MJ, et al: International standards for neurological classification of spinal cord injury (revised 2011). J Spinal Cord Med 34: 535-546, 2011.

15. Wang Y, Yang T, Liu Y, Zhao W, Zhang Z, Lu M and Zhang W: Decrease of miR-195 promotes chondrocytes proliferation and maintenance of chondrogenic phenotype via targeting FGF-18 pathway. Int J Mol Sci 18: E975, 2017.

16. Wang Y, Zhang Y, Yang T, Zhao W, Wang N, Li P, Zeng X and Zhang W: Long non-coding RNA MALAT1 for promoting metastasis and proliferation by acting as a ceRNA of miR-144-3p in osteosarcoma cells. Oncotarget 8: 59417-59434, 2017.

17. Livak KJ and Schmittgen TD: Analysis of relative gene expression data using real-time quantitative PCR and the $2^{-\Delta \Delta C \mathrm{~T}}$ method. Methods 25: 402-408, 2001.

18. Kyrylkova K, Kyryachenko S, Leid M and Kioussi C: Detection of apoptosis by TUNEL assay. Methods Mol Biol 887: 41-47, 2012.

19. Basso DM, Beattie MS and Bresnahan JC: A sensitive and reliable locomotor rating scale for open field testing in rats. J Neurotrauma 12: 1-21, 1995.

20. Wang Y, Wang N, Zeng X, Sun J, Wang G, Xu H and Zhao W: MicroRNA-335 and its target Rock1 synergistically influence tumor progression and prognosis in osteosarcoma. Oncol Lett 13: 3057-3065, 2017.

21. Wang Y, Sun J, Wei X, Luan L, Zeng X, Wang C and Zhao W: Decrease of miR-622 expression suppresses migration and invasion by targeting regulation of DYRK 2 in colorectal cancer cells. Onco Targets Ther 10: 1091-1100, 2017.

22. da Silva Alves E, de Aquino Lemos V, Ruiz da Silva F, Lira FS, Dos Santos RV, Rosa JP, Caperuto E, Tufik S and de Mello MT: Low-grade inflammation and spinal cord injury: Exercise as therapy? Mediators Inflamm 2013: 971841, 2013.

23. Ren Y and Young W: Managing inflammation after spinal cord injury through manipulation of macrophage function. Neural Plast 2013: 945034, 2013

24. Corrêa SA and Eales KL: The role of p38 MAPK and its substrates in neuronal plasticity and neurodegenerative disease. J Signal Transduct 2012: 649079, 2012.

25. Kroner A, Greenhalgh AD, Zarruk JG, Passos Dos Santos R, Gaestel M and David S: TNF and increased intracellular iron alter macrophage polarization to a detrimental M1 phenotype in the injured spinal cord. Neuron 83: 1098-1116, 2014.

26. Sedger LM and McDermott MF: TNF and TNF-receptors: From mediators of cell death and inflammation to therapeutic giants-past, present and future. Cytokine Growth Factor Rev 25: 453-472, 2014.

27. Zelová $\mathrm{H}$ and Hošek J: TNF- $\alpha$ signalling and inflammation: Interactions between old acquaintances. Inflamm Res 62: 641-651, 2013.

28. Tietz AB, Malo A, Diebold J, Kotlyarov A, Herbst A, Kolligs FT, Brandt-Nedelev B, Halangk W, Gaestel M, Göke B, et al: Gene deletion of MK2 inhibits TNF-alpha and IL-6 and protects against cerulein-induced pancreatitis. Am J Physiol Gastrointest Liver Physiol 290: G1298-G1306, 2006.

29. Pelletier SJ, Lagacé M, St-Amour I, Arsenault D, Cisbani G, Chabrat A, Fecteau S, Lévesque M and Cicchetti F: The morphological and molecular changes of brain cells exposed to direct current electric field stimulation. Int J Neuropsychopharmacol 18: pyu090, 2014.

This work is licensed under a Creative Commons Attribution-NonCommercial-NoDerivatives 4.0 International (CC BY-NC-ND 4.0) License. 